\title{
UNA LECCIÓN DE HUMILDAD O CÓMO DEJAR DE SER \\ CRISTIANO PARA INTENTAR SERLO. \\ REFLEXIONES KIERKEGAARDIANAS
}

\author{
Ángel Enrique Garrido Maturano \\ CONICET-IIGHI, Resistencia, Argentina
}

\section{Resumen}

A partir de la crítica que hace Kierkegaard a quienes tienen la ilusión de ser cristianos, el artículo persigue dos objetivos. Primero explicitar qué significa ser cristiano. Segundo determinar cómo es posible romper la ilusión y convertir al otro al cristianismo. Respecto del primer objetivo sostiene que es imposible ser cristiano y que se debe reconocer humildemente que sólo se puede intentar serlo. Respecto del segundo, afirma que es imposible convertir al otro y sólo se puede, humildemente, prepararlo para que intente ser cristiano. Finalmente indica en qué medida un trabajo sobre esta temática puede tener significación filosófica.

Palabras clave: Cristianismo, objetividad, subjetividad, contemporaneidad, absoluto.

\section{Abstract}

From the criticism that Kierkegaard makes to those who have the illusion of being Christian, this article pursues two objectives. First, to explain what it means to be a Christian. Second, to determine how it is possible to break the illusion and convert the other to Christianity. Regarding the first objective, it is argued that it is impossible to be a Christian, and that one must humbly acknowledge that one can only try to be one. Regarding the second, the author claims that it is impossible to convert the other, and one can only humbly prepare him to try to be Christian. Finally, he indicates to what extent a work on this subject can have philosophical significance

Key words: Christianity, objectivity, subjectivity, contemporaneity, absolute. 


\section{Introducción}

Constatando una obviedad, en Mi punto de vista Kierkegaard observa que "la mayor parte de la cristiandad se imagina solamente que es cristiana" Sin embargo, "vive en categorías estéticas o, como máximo, en categorías estético-éticas" ". Su mayor preocupación-podría decirse-no es relacionarse con Dios, sino una buena vida burguesa, entre cuyas notas sociales distintivas figura proclamarse cristiano. Con una indignación a la que no le cabe mejor adjetivo que justa, agrega el danés:

¡Gente que nunca entra en una iglesia, que nunca piensa en Dios, nunca menciona Su nombre, excepto en los juramentos! ;Gente a la que nunca se le ha ocurrido que puede tener alguna obligación hacia Dios (...) es cristiana, se llama cristiana, es reconocida como cristiana por el Estado (...)! ${ }^{3}$

En las citas precedentes se condensa el que, para Kierkegaard, constituye el mayor problema religioso de la cristiandad, a saber, que su proclamado cristianismo no es otra cosa que una "prodigiosa ilusión" ${ }^{4}$. Planteado de esta suerte, el problema religioso nos fuerza a formularnos dos interrogantes que resultan, por cierto, inevitables. Primero: ¿qué significa ser un cristiano verdadero? Segundo: ¿cómo se logra romper la ilusión y ayudar a la cristiandad a volverse en verdad cristiana? Estas dos cuestiones -sin duda esenciales para abordar un problema que aqueja hoy a la cristiandad no menos de lo que lo hacía en los días de Kierkegaard- definen los dos objetivos temáticos de las reflexiones que aquí comienzan. El primero no puede ser otro que explicitar el significado, en el contexto del pensamiento kierkegaardiano, de "ser" cristiano y no sólo de considerarse a sí mismo como tal. El segundo radica en elucidar cómo y hasta qué punto es posible transformar un cristiano ilusorio en uno genuino.

En Ejercitación del cristianismo Kierkegaard nos dice que el existente "ha de humillarse cuando se pregunta por lo que significa ser cristiano en el sentido más riguroso (...)" exige de cada uno, el que delante de Dios sinceramente se humille bajo las

${ }^{1}$ Søren Kierkegaard, Mi punto de vista, trad. de J. M. Velloso, Madrid: Aguilar, 1983, p. 48.

${ }^{2}$ Ibidem.

${ }^{3}$ Ibíd., pp. 45-46.

${ }^{4}$ Ibíd., p. 45.

${ }^{5}$ Søren Kierkegaard, Ejercitación del cristianismo, trad. de D. Gutiérrez Rivero, Madrid: Trotta, 2009, p. 88. 


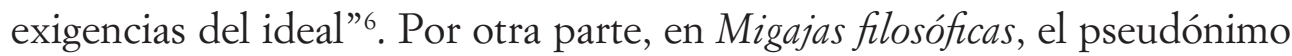
Johannes Climacus, asevera que "si el que aprende ha de recibir la verdad, será preciso que el maestro se la aporte; y no sólo eso, sino que ha de darle también la condición para comprenderla" ". En cuanto a lo que esa condición sea, cuando de lo que se trata es de acceder a un cristianismo verdadero, Kierkegaard concreta la idea de Climacus y no duda en sentenciar que "la única puerta de acceso al cristianismo es la conciencia del pecado" ${ }^{\text {. Si las }}$ citas de Mi punto de vista nos colocaban ante los interrogantes que definen los objetivos de este ensayo, las aseveraciones de Climacus en Migajas y del propio Kierkegaard en Ejercitación nos inducen a formular, a modo de hipótesis, dos posibles respuestas a aquellos interrogantes. La primera hipótesis se basa en la idea de que la ilusión del cristianismo no consiste en creer que ser cristiano es una cosa, cuando en realidad es otra, y que, por tanto, aprendiendo y creyendo en esa otra cosa, uno sería cristiano. La ilusión consiste, por el contrario, en no darse cuenta de aquello que la primera hipótesis afirma, a saber, que no es posible ser cristiano. El cristianismo no es un estado permanente del individuo. No es un patrimonio que se pudiese poseer. No es una substancia que está siempre presente por debajo de los accidentes representados por mis actos vitales. No se lo puede tener hoy y guardarlo para mañana - y para todos los días hasta que llegue el último. Un hombre honesto consigo mismo no puede, en síntesis, decir que es cristiano. Antes bien, según esta hipótesis interpretativa, el verdadero cristiano no es aquel que es cristiano, sino el que se humilla e intenta serlo. La segunda hipótesis se basa en la idea de que la ruptura de la ilusión de la cristiandad requiere que se les enseñe a los ilusos no sólo la verdad del cristianismo, sino, ante todo, la condición necesaria -la conciencia del pecado- para intentar volverse cristiano. Sin embargo, por ser esta condición una toma de conciencia, esto es, una decisión interior y subjetiva, no es posible que nadie deje su cómoda ilusión y se vuelva cristiano porque algún otro lo convenza de una doctrina. Por lo tanto -y he aquí la segunda hipótesisnadie puede volver a otro cristiano. Como dice Kierkegaard, bien puede emplear un hombre la vida en mostrar aquella condición y no lograr nada?

${ }^{6}$ Ibidem.

${ }^{7}$ Søren Kierkegaard, Migajas filosóficas o un poco de filosofía, en Escritos de Søren Kierkegaard. Vol 4/2, trad. de D. González y Ó. Parcero, Madrid: Trotta, 2016, p. 35.

${ }^{8}$ Søren Kierkegaard, Ejercitación del cristianismo, p. 88.

${ }^{9}$ Cfr. Søren Kierkegaard, Mi punto de vista, p. 50. Sin embargo, una vida de ese tipo -aclara Kierkegaard- no sería tampoco en vano, porque sería una vida abnegada, que ha intentado, una y otra vez, ser ella misma cristiana. 
Así definidas, a saber, a través de la afirmación de que no es posible ser cristiano y de que no es posible volver a otro cristiano, las hipótesis parecen meramente negativas, sin embargo, son dialécticas y de su negatividad surge, como espero pueda verse, su positividad intrínseca.

Hemos definido los objetivos temáticos y las hipótesis interpretativas que habrán de articular nuestra lectura del modo en que Kierkegaard afronta el problema del divorcio entre el cristianismo y la cristiandad. Permítasenos para terminar esta introducción alguna precisión metodológica. En cuanto nos proponemos explicitar y configurar, a través de la puesta en diálogo de distintos textos kierkegaardianos, lo que permanece implícito como mera posibilidad de sentido en el tratamiento que Kierkegaard hace del cristianismo, el método de lectura se comprende a sí mismo como bermenéutico. Sin embargo, no se trata de una hermenéutica de tipo filológico, sino de lo que podríamos llamar una hermenéutica filosófica de la facticidad. En efecto, no me interesa tanto comprender intrínsecamente uno o más textos referidos al cristianismo en Kierkegaard a través del análisis erudito e inmanente de esos textos, cuanto explicitar las condiciones de posibilidad e implicancias del factum de la relación con Dios, concebido como lo Absoluto, a partir de ellos. Con el término factum aludo al hecho de que esta relación con lo Absoluto efectivamente se da de un modo u otro en la existencia cristiana y que, cuando ella es genuina, presupone ciertas condiciones e implicancias que aquí intentaremos explicitar. Por ello mismo hablamos de una hermenéutica de la facticidad y de un enfoque filosófico y no filológico. Por ello también la investigación no tiene por qué renunciar a establecer libremente, en función de la propia perspectiva e intereses, conexiones entre distintos textos, ya sea que los haya firmado Kierkegaard o alguno de sus múltiples pseudónimos ${ }^{10}$.

${ }^{10}$ Lo que distingue esencialmente un enfoque hermenéutico filosófico de uno filológico radica en su perspectiva. El enfoque filológico quiere comprender un texto o varios textos determinados y la figura del pensamiento que ellos despliegan; el filosófico pretende analizar en qué medida esos textos describen un aspecto constitutivo o esencial del fenómeno en cuestión. En el fondo los dos enfoques metodológicos, aunque divergentes, no son opuestos, sino complementarios. No son opuestos porque su objeto es diferente: en un caso un fenómeno fáctico es un pretexto para comprender un texto, en el otro un texto una vía para comprender un fenómeno. Y son complementarios, porque el análisis del aspecto o esencia de una figura del pensamiento en determinados textos -en este caso la concepción kierkegaardiana del cristianismo- implica la comprensión de la esencia de esa figura. 
Ahora bien, si lo que aquí intentará desplegarse es una hermenéutica filosófica del factum de la relación con lo Absoluto en el cristianismo, entonces en dicha hermenéutica, en tanto que filosófica, anida oculto un tercer objetivo, que ya no es temático, sino epistémico, a saber, determinar en qué medida (y en cuál no) un análisis que versa sobre lo que significa ser cristiano y cómo uno puede convertirse genuinamente en tal puede considerarse no sólo un escrito religioso, sino también una reflexión de alcance filosófico. A este último objetivo conducen, en última instancia, el derrotero por los objetivos precedentes de la mano del método elegido.

\section{Qué significa ser cristiano \\ 1. Imposibilidad objetiva de ser cristiano}

Hacia el final del Postcriptum, poco antes del apéndice, KierkegaardClimacus aborda directamente la cuestión de lo que significa ser cristiano. El abordaje es, si se me permite, una suerte de fenomenología avant la lettre. Lo es en la medida en que el cristianismo resulta en esencia relación con Dios; y esta relación es descripta en términos de una correlación que se juega entre un polo subjetivo y otro objetivo, a saber: entre un modo subjetivo de intencionar o dirigirse a lo Absoluto y un correlato objetivo a quien se dirige la intención, que es lo Absoluto mismo o Dios, tal cual el cristianismo lo entiende. En una primera instancia Climacus se centra en el polo objetivo e intenta determinar si es posible volverse cristiano objetivamente, es decir, por afirmar la doctrina correcta -sea ésta cual fuere- del cristianismo sobre Dios. Ese intento conduce al fracaso. En efecto, si el "qué" de la doctrina es lo que decide si uno es cristiano, entonces la intencionalidad se dirige hacia algo externo, por ejemplo, la correcta exégesis de la Biblia, a fin de averiguar de modo puntilloso cuál es la recta doctrina cristiana. "En ese preciso instante da inicio la erudita, ansiosa y atemorizada contradicción de la aproximación"11.

Es una aproximación asintótica que no convierte a nadie en cristiano. Y ello por dos razones. En primer lugar, porque Dios es lo Ab-soluto e Infinito; eo ipso ninguna doctrina ni representación finita pueden ni definirlo ni contenerlo. En consecuencia, toda relación con un qué objetivo no es una

${ }^{11}$ Søren Kierkegaard, Postscriptum no cientifico y definitivo a Migajas Filosóficas, trad. de N. Bravo Jordán, México: Universidad Iberoamericana, 2008, p. 610. 
relación con Dios. Pero, además, por una segunda razón, a saber, porque de lo que se trata no es determinar cuál es el cristianismo correcto, sino si yo soy cristiano, esto es, "la decisión en virtud de la cual el individuo se vuelve cristiano" 12 . La tarea es que el sujeto se vuelva interiormente cristiano y la ilusión más peligrosa de todas es estar seguro de que uno es cristiano porque cree saber cuál es la doctrina exterior del cristianismo. Sin embargo, podría objetarse que no se trata del contenido objetivo de la doctrina, sino de creer en ese objeto, de estar dispuesto a vivir y morir por él. Aquí surge un nuevo problema que el autor pseudónimo ve con agudeza. El análisis empieza a desplazarse de lo objetivo a lo subjetivo, al modo de apropiación del objeto, pero, al no especificarse este modo suficientemente, la decisión termina supeditándose a lo objetivo. En efecto, el amante también cree en la amada, el patriota en la patria y el avaro en las divisas - y todos ellos están dispuestos a vivir y morir por aquello en lo que creen. Por lo tanto, el mero modo de apropiación del contenido objetivo, cuando esta apropiación es definida en términos de creencia y aferramiento, no distingue suficientemente la interioridad del cristiano de cualquier otra, "de suerte que es preciso regresar al 'qué' de la doctrina” y, de ese modo, a los problemas que señalamos al principio. Queda claro, pues, que el camino objetivo no nos conduce a ser cristianos, que no es posible ser cristiano por la mera adhesión o creencia de tipo intelectual en una doctrina cualquiera. Esta adhesión debe ser de un tipo muy específico que se distinga de cualquier otra creencia ciega. Por ello la marca del cristiano no es un hecho objetivo como el bautismo, la proclamación de un cierto credo, la participación en tales o cuales ritos y cultos, el apoyo de determinadas prácticas y la vituperación de otras, sino que la marca del cristianismo es una interioridad específica y distintiva, gracias a la cual la espiritualidad del cristiano se diferencia esencialmente de cualquier otra actividad espiritual humana ${ }^{13}$. ¿Será posible, pues, por esta vía subjetiva e interior ser cristiano?

${ }^{12}$ Ibidem.

13 Aquí es necesario para el lector no especializado recordar que el espíritu, para Kierkegaard, es la esencia de la condición humana. Dicha esencia radica en que el sí mismo es una relación que, en su relación con lo otro que sí, se relaciona y determina a sí mismo. En esa misma medida es libre. Sin embargo, el sí mismo decide la relación que él es, pero no decide ser una relación que se relaciona a sí. El sí mismo es puesto o dado a sí mismo como espíritu. Ahora bien, si no somos nosotros mismos quienes nos hemos puesto como tal, tampoco pudimos ser puesto como espíritu por ningún otro ente natural, porque el conjunto de los entes (ontos) determinados por las leyes de la naturaleza (logos) o bien son entes encerrados en sí y sin relación con lo otro, o bien se relacionan con su mundo 


\section{Imposibilidad subjetiva de ser cristiano}

Si ser cristiano no se define por el "qué" del cristianismo, debiera definirse por el "cómo" del cristiano. "Este 'cómo' -observa genialmente Climacus- se adapta a una sola cosa: la paradoja absoluta" ${ }^{14}$. ¿Cuál es la paradoja absoluta? La paradoja no es otra que pretender que el Dios omnipotente se haya vuelto hijo de un carpintero en la persona de Cristo; que El Eterno se haya encarnado en la historia; que El Inmortal haya perecido en la cruz. Y esta paradoja es un escándalo. ¿Por qué? Es un escándalo para la razón, porque, al referir a Dios a un sujeto contingente e histórico (Cristo), se vuelve imposible una representación objetiva un concepto racional- de Dios. Dicho de otro modo, al correlacionar la apropiación interior con una paradoja, se la correlaciona con aquello que no es susceptible de ser determinado ni como una verdad de razón ni como un hecho verificable. Desde este momento la apropiación interior queda referida a una incertidumbre objetiva. Este escándalo es, sin embargo, lo que salva tanto la especificidad de la fe cuanto la especificidad de Dios como aquello intencionado por la fe del cristiano.

¿De qué manera el escándalo salva la especificidad de Dios? La respuesta es simple: la paradoja, que ocasiona el escándalo, mantiene a lo divino en la incognoscibilidad. "¿Qué es la incognoscibilidad? Incognoscibilidad es no ser en sus caracteres lo que se es esencialmente?" ${ }^{15}$ ¿Y por qué Dios debiera anunciarse con caracteres tales que permaneciese incógnito? Porque ésta es la única manera de no devenir un ídolo. Todo lo que es susceptible de ser conocido por el hombre es finito. Si Dios pudiera anunciarse de un modo y manera tal que fuese conocido en sus rasgos esenciales, Él sería un Dios

circundante, pero no se relacionan con esa relación. En consecuencia, el espíritu testimonia en el orden del ser -en el orden ontológico- lo Otro que ser que lo ha puesto como tal. Esto Otro, que se ab-suelve de toda determinación objetiva, pues escapa al orden al que se aplica el logos, es a lo que Kierkegaard llama "el Poder" o "Dios". Pues bien, la marca de la interioridad cristiana radica en que a través de sus relaciones con lo otro que sí, no se relaciona no sólo con eso otro objetivo, ni consigo mismo a través de eso otro objetivo, sino también, al mismo tiempo, con el Poder que lo ha puesto como espíritu. El espíritu que se relaciona con lo otro sin determinarse a sí en esa relación existe en el plano estético. El que se relaciona a sí en su relación con lo otro en el ético. El que se relaciona a aquello que lo puso como la relación que él es relacionándose a sí en la relación con lo otro existe en el plano religioso.

\footnotetext{
${ }^{14}$ Søren Kierkegaard, Postscriptum, p. 613.

15 Søren Kierkegaard, Ejercitación del cristianismo, p. 143.
} 
finito, verbigracia, un ídolo ${ }^{16}$. La incognoscibilidad del Dios-hombre es un incógnito que mantiene el carácter absoluto de la divinidad y -advierte Kierkegaard- "la seriedad divina consiste cabalmente en que se mantiene [este carácter] hasta tal punto que Él mismo en cuanto puro hombre sufrió bajo la incognoscibilidad" ${ }^{17}$. He aquí, pues, lo específico del Dios cristiano: la seriedad con que el sufrimiento de Cristo, en cuanto escándalo, sostiene la incognoscibilidad divina. A este modo serio, pero escandaloso de comunicarse para una razón que quiera desesperadamente ser la medida de todas las cosas, lo llama el danés, como es bien sabido, "comunicación indirecta”. Como el Dios-hombre no puede sino rehusar a la comunicación directa y al consecuente conocimiento objetivo, él no puede sino reclamar fe. ¿Cuál es la especificidad de esta fe cristiana reclamada por la paradoja?

La respuesta también es sencilla. Sus implicancias no tanto. Lo específico de la fe es ser una decisión libre que toma como verdad absoluta una incertidumbre objetiva. Si Dios se hubiese comunicado de modo directo, en su magnificente omnipotencia, si fuese objetivamente irrefutable la existencia del Eterno, entonces la fe no sería una decisión libre, sino la aceptación racional de una consecuencia necesaria. Pero esta decisión libre no se limita a afirmar una incertidumbre objetiva, sino que lo hace con toda la pasión de la interioridad ${ }^{18}$, de modo tal que esta incertidumbre deviene para el existente la verdad absoluta y última a la cual habrá de supeditarse su existencia entera. Así comprendida, la fe religiosa ya no se acomoda a la creencia del patriota, del avaro o del amante, que pueden determinar aquello en lo que creen y que están ciertos de su existencia objetiva, sino

${ }^{16}$ Esta argumentación muestra que, si bien la paradoja es irracional y escandalosa, su necesidad y significado pueden ser comprendidos por el pensamiento. En este sentido afirma Arne Grøn: "Sin embargo la paradoja exige una comprensión. Es necesario comprender, que se trata de la paradoja y no de cualquier sinsentido. Esta comprensión, exigida por la paradoja, va incluso más allá, pues se puede preguntar lo que la paradoja significa”. Angst bei Søren Kierkegaard. Eine Einfübrung in sein Denken, trad. (alemana) U. Lincoln, Stuttgart: Klett-Cotta, 1999, p. 176. La afirmación de Grøn de que la paradoja implica comprensión no es un detalle menor, pues refuta la desatinada idea, para mi gusto aún demasiado difundida, de que Kierkegaard sería un fanático religioso defensor de la irracionalidad. Por el contrario, su análisis del significado del cristianismo como paradoja muestra que su tratamiento de la cuestión es filosófico-trascendental, si por tal entendemos la elucidación de las condiciones de posibilidad de la revelación de lo divino como tal.

${ }^{17}$ Søren Kierkegaard, Ejercitación del cristianismo, p. 143.

${ }^{18}$ En este sentido escribe Climacus: "la fe es, en el escándalo del absurdo, la incertidumbre objetiva sostenida firmemente en la pasión de la interioridad”. Søren Kierkegaard, Postscriptum, p. 613. 
"exclusivamente a aquel que (...) se relaciona con la paradoja absoluta"19. Ahora bien, si, a través de la fe, el cristiano afirma apasionadamente en su interioridad, es decir, para sí mismo y para su entera existencia, una verdad absoluta, aunque objetivamente incierta, entonces lo propio de esa verdad es ser existencial y subjetiva. El carácter absoluto de una verdad tal no se manifiesta en la objetividad de lo Absoluto -que, como tal, es incierto e incognoscible-, sino en el hecho de que su apropiación transforma y determina absolutamente el cómo de mi existencia. En términos de Kierkegaard: "Una incertidumbre objetiva, apropiada firmemente en virtud de la más apasionada interioridad, es la verdad, la más alta verdad que hay para un sujeto existente" 20 . Desde el punto de vista objetivo se tiene, entonces, incertidumbre, porque aquello en que se cree no es propiamente un objeto, sino un escándalo, pero precisamente esta incertidumbre funge como el acicate que lleva a la interioridad a adueñarse con tal pasión y seriedad de aquello incierto, que lo afirma absolutamente, es decir, que compromete por entero cada instante de su vida y de su relación consigo mismo y con el mundo con esa verdad. En este sentido interioridad, como observa atinadamente Michel Heymel, "no es huida del mundo o retracción del mundo, sino una relación tensa y apasionada con el mundo, que conlleva a la vez sufrimiento y acción, es pathos existencial" 21 . La apropiación interior de la revelación de Dios en Cristo implica, entonces, no un mero convencimiento intelectual de que el cristianismo es la verdadera religión (pues esto es objetivo, y aquí no hay ninguna verdad objetiva), sino determinar mi entero "ser-en-el mundo" sobre la base de mi relación con lo Absoluto que se revela en la paradoja. Esto, y nada menos que esto, es la exigencia implícita en la fe cristiana. Esta exigencia la expresa Kierkegaard, como ha observado J. Wahl, en la noción de "contemporaneidad" con Cristo ${ }^{22}$. Podemos, entonces, sintetizar lo desarrollado en este punto haciendo hincapié en que ser cristiano desde el correlato subjetivo significa tener fe en el escándalo representado por Cristo. Ello, por su parte, implica relacionarse con Cristo como verdad subjetiva

\section{${ }^{19}$ Ibidem.}

${ }^{20}$ Ibíd., p. 206. (Cursivas del autor).

${ }^{21}$ Michael Heymel, Christian Möller, Das Wagnis. Ein Einzelner zu sein. Glauben und Denken Søren Kierkegaards am Beispiel seiner Reden, Zürich: Theologischer Verlag, 2013, p. 71.

${ }^{22}$ En sus ya antiguos, pero deningún modo viejos, Études Kierkegaardiennes, afirma Jean Wahl: "La fe es esencialmente contemporaneidad”. Jean Wahl, Études Kierkegaardiennes, París: Vrin, 1967, p. 296. A mi modo de ver, éste, a pesar de su antigüedad, continúa siendo el mejor estudio filosófico de conjunto del pensamiento de Kierkegaard. 
absoluta. Relacionarse con Cristo como verdad subjetiva absoluta conlleva, a su vez, transformar mi entera existencia a cada instante en función de esa verdad que es Cristo. $Y$ hacer tal cosa significa, en términos concretos, ser contemporáneo de Cristo. En palabras del propio Kierkegaard: "Si no logras superarte a ti mismo hasta ser cristiano en situación de contemporaneidad con Él, (...), entonces jamás llegarás a ser cristiano" ${ }^{23}$. Pero seamos aún más concretos. ¿A qué se alude cuando se exige ser contemporáneo de Cristo?

Para comprender cabalmentela relación subjetiva de contemporaneidad es menester, ante todo, tener constantemente presente que Kierkegaard concibe al Dios-hombre como lo Absoluto ${ }^{24}$. Consecuentemente habrá que precisar aún más las características de la relación con lo Absoluto. ¿Qué es lo Absoluto? Esta pregunta, como es obvio, no tiene otra respuesta posible que la tautológica: lo Absoluto es Dios. De otro modo, si lo Absoluto fuera determinable, no sería Absoluto. Sin embargo, la relación con lo Absoluto sí puede ser caracterizada. A mi modo de ver, tres rasgos son los que mejor la reflejan. El primero es su incondicionalidad. La relación con lo Absoluto debe tomar lo Absoluto absolutamente. Y ello ocurre sólo si esa relación es un fin incondicional, al que debo encaminarme cualquiera sea mi situación y no sólo en tales o cuales condiciones. En consecuencia, a mi relación con lo Absoluto deben supeditarse todas las otras relaciones que mantengo con cualquier realidad finita. En caso contrario, sería para mí esa realidad finita mejor o, por lo menos, tan buena como Dios. Y negar que Dios es absolutamente bueno es, por antonomasia, pecado. El segundo, que no es sino un corolario del primero, es su totalidad. No me relaciono en un cierto aspecto religioso de mi vida con lo Absoluto, mientras que, por otro carril, discurre mi vida comercial, en la que persigo mi beneficio sin preocuparme en nada de lo Absoluto; mi vida política, en la que generalmente también persigo mi beneficio; o mi vida amorosa en la que corro anhelante detrás de un placer tan efímero como mis beneficios mercantiles y políticos. No. Todos y cada uno de los aspectos y los actos de mi vida han de estar dirigidos y subordinados a lo Absoluto, de modo que debo renunciar a cualquier contento y relación finita, si aquel contento y esta relación no me ponen en el camino que de mi exige lo Absoluto. En caso contrario, mi relación con lo Absoluto no sería absoluta, sino finita; y una relación

${ }^{23}$ Søren Kierkegaard, Ejercitación del cristianismo, p. 86.

24 "Con la invitación a 'todos los que están atribulados y cargados' ha venido el cristianismo al mundo, no, como proclaman gimoteando y falsamente los párrocos, como una edición lujosa de dulces consuelos, sino como lo Absoluto”. Ibíd., p. 84. 
finita lo es siempre con algo que es considerado finito. Y negar que Dios es lo Infinito es, por antonomasia, también pecado. El tercer rasgo, que se deriva de los dos precedentes, es su realidad efectiva. Si de lo que se trata es de relacionarse con lo Absoluto, nada puede ser más real ni vivo para mí, nada puede estar más presente a mi conciencia a cada instante, que mi compromiso total e incondicional con lo Absoluto. Si así no fuera, si lo Absoluto no estuviese presente en el acontecer efectivo de mi existencia y si mi relación con él fuese un grato recuerdo del pasado o una noble intención para el futuro, propiamente lo Absoluto no sería ni real ni eterno para mí, dado que lo real y lo eterno, lo eternamente real, está presente a cada instante. Y negar que Dios es real y eterno resulta, por antonomasia, de nuevo, pecado. La contemporaneidad, en tanto modo por excelencia de relación absoluta con lo Absoluto, se determina, entonces, por las tres características que acabamos de reseñar. En primer lugar, en la relación de contemporaneidad con Cristo, mi relación con lo Absoluto constituye el fin último de mi existencia, al cual supedito cualquier otra relación, no importa cuál fuese el beneficio personal o el placer que ella me provocase. En segundo, en la relación de contemporaneidad me comprometo por completo, comprometo el conjunto de mi existencia con lo Absoluto. Y en tercero, la relación de contemporaneidad acontece en el presente, a cada instante presente, porque sólo si en cada presente Dios constituye el fin último al que oriento, entrego y confío toda mi existencia, Él es absolutamente real y eterno -constantemente presente- para mí. Por ello puede decir Kierkegaard que "en relación con lo Absoluto solamente se da un tiempo: el presente" 25 . Y por ello también puede agregar que "aquello con lo que tú vives, aquello de lo que eres contemporáneo, es realidad para ti" ${ }^{26}$. La fe es, pues, esencialmente contemporaneidad. Como tal, la fe -el relacionarse subjetivamente con Dios- es estar íntegra e incondicionalmente "ante Dios" a cada instante, porque sólo se puede estar "ante Dios" en el presente. No es posible ser cristiano si no se lo es en el presente. No puede uno decir que es cristiano porque lo ha sido o se ha considerado como tal en el pasado o porque se piensa seguir adhiriendo al cristianismo en el futuro. El cristianismo es pura actualidad y no una condición que dura a lo largo del tiempo. Precisamente porque alguien llega a ser cristiano sólo en la contemporaneidad, no es posible, como anticipaba en la introducción, considerar el cristianismo como una característica sustancial y perdurable

${ }^{25}$ Ibíd., p. 85.

${ }^{26}$ Ibidem. 
del individuo; una "quididad" que se obtiene de una vez y para siempre; un patrimonio que se puede atesorar hoy y guardarlo para mañana. El cristianismo se juega a cada instante, debe reconquistarse en cada presente, porque "para aquel que no es contemporáneo de lo Absoluto, lo Absoluto no existe en modo alguno" 27.

¿Hemos concretado, con este giro de la exposición en dirección a la contemporaneidad, suficientemente el "cómo" del ser cristiano? Aún no, si no aclaramos, como lo hace el propio Kierkegaard, que sólo se es verdaderamente contemporáneo con Cristo si se es contemporáneo "con la vida de Cristo sobre la tierra" 28 . Lo cual significa vivir del modo y en la situación que Cristo vivió sobre la Tierra. Pues si no puedes tolerar que la situación de Cristo, con el horrible sufrimiento y humillación que la acompaña, "es tu misma situación y no caes de rodilla y lo adoras: es que no eres cristiano esencialmente" 29 . Pero vivir en el modo y en la situación en que lo hizo Cristo, sacrificando su vida entera a ese Absoluto inasible que llamamos Reino de Dios, no puede acontecer concretamente sino a través de la siempre renovada imitación de Cristo. Y justo ésta es la conclusión a la que llega Kierkegaard cuando sentencia: "La prueba de lo cristiano consiste realmente en la «imitación»" ${ }^{30}$. Sólo quien se aventura más y más, un instante tras otro, en la imitación de Cristo, vive en relación con lo Absoluto. Sólo a él se le puede decir, como bellamente lo dice el filósofo, que "la certeza en relación a la ascensión a los cielos llega de inmediato" 31 .

La definición subjetiva del cristiano, el "cómo" del ser cristiano, se define, entonces, como contemporaneidad; y la contemporaneidad se expresa como imitación de Cristo. ¿Pero hay alguien que pueda vivir cada presente imitando a Cristo y cargando sobre sus espaldas el infinito sufrimiento y la infinita humillación que él cargó? ¿Hay alguien que pueda vivir cada instante entregando toda su vida a lo Absoluto, al advenimiento de ese sentido absoluto y perfecto para todos los seres, a esa "felicidad eterna" que llamamos Reino, y cuya esencia y existencia objetiva nos es ignota? ¿Hay alguien cuyo presente nunca se haya agotado en el gozo inmediato de lo finito? ¿Hay uno solo que alguna vez no haya antepuesto el tierno calor de la amada y el rotundo sabor del vino al advenimiento del

${ }^{27}$ J. Wahl, Études Kierkegaardiennes, p. 396.

${ }^{28}$ Søren Kierkegaard, Ejercitación del cristianismo, p. 86.

${ }^{29}$ Ibidem.

${ }^{30}$ Søren Kierkegaard, Para un examen de sí mismo recomendado a este tiempo, trad. de A. Albertsen, Madrid: Trotta, 2011, p. 86.

${ }^{31}$ Ibíd., p. 88. 
Reino? Si respondemos honestamente, no cabe sino concluir que nadie es, de modo definitivo, esencial y perdurable, cristiano. De nadie sabemos que haya subido inmediatamente a los cielos. La prueba de la tesis no es lógica, sino existencial, porque es una tesis existencial: no es posible ser cristiano. La exigencia del ideal es tan alta que la condición de cristiano es imposible y quien así se define o es un mentiroso o vive en una ilusión. ¿Pero si resulta imposible, tanto desde el punto de vista objetivo cuanto subjetivo, ser cristiano, entonces qué? Entonces la humildad.

\section{La bumildad}

La medida que pone la vida de Cristo, transmitida por los Evangelios, a la totalidad de la existencia del individuo resulta tan alta que el hombre honesto, que se toma en serio el cristianismo y su exigencia de contemporaneidad, no puede sino, con humildad, decirse a sí mismo:

No sirvo para hacer algo a medias - y este libro, la Palabra de Dios, es un libro sumamente peligroso para mí, y es un libro tiránico: si se le da un dedo, se toma toda la mano; si se le da toda la mano, se toma al hombre entero y tal vez transforme de pronto toda mi vida de acuerdo con una medida inmensa. No, sin (cosa que detestaría), sin permitirme ni una sola palabra burlona y peyorativa sobre este libro; lo llevo a un lugar apartado; no quiero estar a solas con él'32.

Si este mismo hombre honesto, quisiera, a pesar de todo, ser cristiano, no le quedaría otra opción que reconocer humildemente que no puede a cada instante llevar una relación absoluta con lo Absoluto, es decir, que no puede evitar tomar lo Absoluto por relativo; que no puede tampoco dejar de sucumbir a la tentación de preferir una realidad finita que una infinita; que, en suma, sus trabajos y sus días testifican una y otra vez que para él lo Absoluto no tiene, las más de las veces, realidad efectiva. Para decirlo en una palabra: a este hombre honesto no le queda sino confesarse bumildemente a sí mismo que ha pecado, pues esto es en esencia el pecado: tomar lo Absoluto -a Dios mismo- por relativo y lo relativo -mis intereses finitos-por lo Absoluto. Por eso mismo afirma Kierkegaard: "La única puerta de acceso al cristianismo es la conciencia del pecado; y todo otro camino para querer introducirse

\footnotetext{
${ }^{32}$ Ibíd., p. 49.
} 
en él es pecado de lesa majestad contra el cristianismo"33. Lo es, porque no significaría creer que uno puede ponerse al servicio de lo Absoluto y una y otra vez intentar imitarlo sin lograrlo por completo nunca, sino estar convencido de que uno puede ser absoluto. He aquí la esencia del pecado satánico. En cambio, el hombre humilde, que reconoce que es pecador, que lo es personalmente por propia decisión y que no puede por sí mismo estar a la altura que la vida de Cristo impuso, no se cree absoluto. Tampoco necesita para ser cristiano conocer con puntillosidad la Biblia, ni practicar escrupulosamente todos los rituales, ni, hincado, agotar las horas rezando. Le basta esto tan sencillo y, sin embargo, tan difícil: ser honesto ante sí y ante los otros y tener el humilde convencimiento de que es personalmente pecador. Pero si le faltara este convencimiento, entonces de nada le valdrían las jornadas dedicadas al estudio de la Biblia, ni el cumplimiento minucioso de los ritos, ni tampoco haberse pelado las rodillas. Por eso "para el religioso la humildad representa la determinación límite"34.

Es en este punto donde finalmente se revela qué significa, en el horizonte del pensamiento de Kierkegaard, ser cristiano. Ser cristiano es imposible si por tal se entiende -repito- poseer el cristianismo como una condición o determinación esencial, de la que el individuo pudiera adueñarse y tomar posesión indefinida. Ninguna práctica cultural objetiva o adhesión dogmática alcanzan para llamarse cristiano. Pero tampoco ninguna contemporaneidad con Cristo es asumida en la interioridad con suficiente intensidad y pasión como para decirse cristiano. El cristianismo, antes que una condición, es una ejercitación. Es el renovado intento de, al menos en algunos y señalados instantes de la vida, decidirse a imitar Cristo y servir al advenimiento del Reino lo mejor que se pudiese. Es un intento quijotesco que, por su desmesura, una y otra vez fracasa. Pero si existe humildad y, consecuentemente, conciencia del pecado, una y otra vez puede ser retomado. Propiamente hablando, uno no es cristiano, sino que, a lo sumo, intenta serlo. La única certeza posible de que se lo ba intentado en serio es la conciencia del pecado. Quien tiene esta conciencia sabe que no es Absoluto ni suficientemente digno de lo Absoluto con lo que quiere relacionarse. Y quien esto sabe, respeta el carácter absoluto de lo Absoluto: "Sólo la conciencia del pecado, al ser el absoluto respeto, es el acceso [al cristianismo]" 35 .

${ }^{33}$ Søren Kierkegaard, Ejercitación del cristianismo, p. 88.

34 Almut Furchert, Das Leiden Fassen. Zur Leidensdialektik Søren Kierkegaards, Freiburg/München: Alber, 2012, p. 256.

35 Søren Kierkegaard, Ejercitación del cristianismo, p. 89. 
¿Vivirá quien intenta ser cristiano y tiene conciencia del pecado lleno de remordimientos, torturándose a sí mismo sin cesar, ahogado en un mar de lágrimas, martirizado por las penitencias? Nada de eso. Vivirá normalmente, como cualquier otro hombre, esforzándose todo lo que puede en cumplir sus deberes y sin cumplirlos nunca a la perfección. Ahorrará a los demás todo gesto altisonante y todo aspaviento exterior que no deje dudas de que él sí es cristiano, porque sabe que no se puede ser cristiano en sentido riguroso y que incluso "la más decisiva expresión externa es solamente relativa, es al mismo tiempo demasiado y demasiado poco, demasiado porque demuestra arrogancia ante los demás, demasiado poco porque, a fin de cuentas, sigue siendo una expresión terrena" ${ }^{36}$. Con clara conciencia del pecado, pero también con interioridad serena y humilde, se limitará a vivir "ante Dios”, es decir, cierto de su necesidad de Absoluto y aceptando el sufrimiento que implica no poder alcanzarla. Pero como es humilde se confiará a la gracia, que se ofrece a todos los hombres, y que no es sino la esperanza de que lo Absoluto alguna vez lo alcance a él y a cada uno de sus hermanos. Reconfortado por la gracia, en vez de hacer alarde de cristianismo, "se entrega a su trabajo, contento con él, ama a su esposa, contento con ella, educa a sus hijos que son su alegría, ama a sus semejantes, se goza con la vida" ${ }^{37}$. No niega el sufrimiento de la finitud ni su culpa por el pecado, pero tampoco se regodea con el sufrimiento ni se desespera por la culpa. Sale al mundo a vivir y gozar de la vida y, de ese modo, agradece a Dios, que ha creado el mundo, le ha dado la maravilla de la vida y el privilegio de poder gozarla. Así, él se contenta con el milagro de ser hombre y de poder participar, con humildad, pero activamente, en la tarea de la creación ${ }^{38}$. Así intenta cada mañana, cuando sale al mundo y mira el cielo, volverse cristiano.

${ }^{36}$ Søren Kierkegaard, Postscriptum, p. 495.

${ }^{37}$ Søren Kierkegaard, Ejercitación del cristianismo, p. 88.

${ }^{38}$ La idea de que el cristianismo es conciencia del pecado y, por tanto, interioridad ha llevado al malentendido de creer que la religiosidad se esconde en lo puramente subjetivo y no tiene ninguna necesidad de actuar en el mundo. Por el contrario, la relación interior con Dios es determinante para el modo como el individuo es en el mundo. En este sentido escribe Almut Furchert: "La acentuación de la interioridad oculta debe ser considerada conjuntamente con la idea de contemporaneidad: el hombre debe por cierto no sólo llegar a ser interior, sino que en la misma medida debe convertir su existencia en testimonio de esa interioridad”, Das Leiden Fassen. Zur Leidensdialektik Søren Kierkegaards, p. 258. 


\section{Cómo convertir a alguien en cristiano}

Pero para que un individuo intente cada día volverse cristiano, tiene primero que salir de la ilusión -inmensamente extendida en la cristiandad y por completo dominante en las iglesias- de que ya es cristiano. ¿Acaso no se ha bautizado? ¿Acaso no va los domingos a la iglesia y para todo cita la Biblia? ¿Acaso no vota por candidatos que son cristianos como él? Es necesario, pues, que se rompa la ilusión y que se le enseñe que no es posible ser cristiano del modo en que él cree serlo. Es necesario, en otras palabras, que se le enseñe la verdad, puesto que el cristianismo es, desde el punto de vista subjetivo, como vimos, la verdad más alta a la que puede aspirar un hombre. Precisamente en Migajas filosóficas, Climacus se refiere a esta cuestión: ¿Cómo es posible enseñar la verdad? ¿Cómo es posible ser un verdadero maestro? El proceso de enseñanza reconoce tres pasos. El estado previo, la condición y la verdad.

Al estado previo podemos llamarlo la "no-verdad". El discípulo "ha de ser considerado como estando fuera de la verdad (no yendo hacia ella al igual que un prosélito, sino alejándose de ella) o como no-verdad" 39 . Por lo tanto, no vale aquí la mayéutica socrática, pues uno no puede recordar lo que no supo, ni ser lo que no es ni piensa que tiene que ser. De lo que se trata, entonces, no es de que el maestro sea la ocasión para que el discípulo descubra la verdad-que él vive en una ilusión y que no es posible ser cristiano como él cree serlo-, sino de que le aporte la verdad. Según mi modo de ver, el primer paso para que ello ocurra es que el iluso tome conciencia del estado previo en el que está, esto es, de que existe en la no-verdad. Conciencia de que no es cristiano. ¿Y cómo es esto posible? Al respecto, en la Introducción al Postscriptum, el propio Climacus da algunas indicaciones que considero de gran valor. Allí se nos dice que aún sin tener una plena comprensión del cristianismo, al menos ha de comprenderse que el cristianismo es la promesa de la felicidad absoluta y eterna del individuo singular; y que, por tanto, el cristianismo presupone en el individuo un interés infinito por su propia felicidad eterna ${ }^{40}$. Lo que, en consecuencia, puede hacer el maestro es mostrarle que su pretendido cristianismo se basa en relaciones finitas, en puras objetividades limitadas y perecederas. Por lo tanto, el discípulo no puede decirse a sí mismo con sinceridad que él es infinita y eternamente feliz a causa de las cosas por las que se cree cristiano; verbigracia, no goza

${ }^{39}$ Søren Kierkegaard, Migajas filosóficas, p. 34.
${ }^{40}$ Cfr. Søren Kierkegaard, Postscriptum, p. 16.

Estudios Kierkegaardianos. Revista de filosofía 5 (2019) 
infinita ni eternamente de ir al culto, porque el culto termina, y más tarde o más temprano él se preocupa por otras cosas mundanas que el culto no puede satisfacer. Pero quien desea ser cristiano lo que desea es la felicidad eterna-lo Absoluto- y si lo que él desea es tan sólo ir al culto, entonces él no es cristiano ni quiere serlo. En otras palabras, el maestro -y he aquí la única línea de contacto entre la mayéutica y la enseñanza del cristianismo- debe intentar despertar en el iluso su sensibilidad, deseo o interés infinito por la "felicidad eterna". Pero es una línea muy delgada y evanescente, porque, para la mayéutica socrática, todo hombre conoce la verdad y se trata sólo de que la recuerde. El hombre no tiene la posibilidad de borrar por completo de su memoria la verdad que lleva en su interior. Pero, para el cristianismo, que le concede al hombre libertad y a la libertad poder de transformar el individuo y el mundo, es plenamente posible que el hombre, abotagado por la finitud y obsesionado con ella, renuncie por completo a su sensibilidad para con lo Absoluto. Climacus es claro al respecto:

No es cosa imposible que el individuo infinitamente interesado por su felicidad eterna, llegue a ser eternamente feliz algún día; aunque, por otra parte, es a todas luces imposible que el sujeto que ha perdido esta sensibilidad (y esta sensibilidad difícilmente pueda ser otra cosa que una preocupación infinita) sea alguna vez eternamente feliz ${ }^{41}$.

Dicho en otros términos, no es posible que aquel que no renuncie a darle un valor absoluto a lo relativo y que, en consecuencia, no experimente y asuma su necesidad de Absoluto, acepte que está en la no verdad. El maestro puede mostrarle que vive anegado en bagatelas y puede mostrarle que son bagatelas. Un buen camino para ello sería incitarle, dialécticamente, a exigir más y más de una relación estética, es decir, del gozo inmediato de lo finito, para tratar de extraer de esa relación y de ese ímpetu estético una felicidad absoluta y perfecta, de modo tal que se produzca lo inevitable: que experimente el fracaso y la necesidad de que lo estético dé un salto hacia lo religioso ${ }^{42}$. Pero al fin y al cabo es el discípulo el que debe negar la negación del (la doble negación es una afirmación) de todo Absoluto que su vida representa y reconocer que existe en la no verdad. He aquí el primer

${ }^{41}$ Ibíd., p. 17.

${ }^{42}$ Estimo que en este sentido puede leerse la recomendación que hace Kierkegaard en $M i$ punto de vista al escritor religioso para que comience con obras estéticas, cuanto más brillantes mejor, "de forma que con el ímpetu conseguido por la devoción a lo estético entren en contacto con lo religioso”, p. 49. 
límite y la primera imposibilidad para convertir a alguien de la ilusión del cristianismo al cristianismo verdadero: debe producirse en el individuo y sólo en el interior del individuo una toma de conciencia de que existe en la no-verdad. "La propia no-verdad únicamente puedo descubrirla por mí mismo" ${ }^{43}$. Nadie puede volver a otro cristiano. El iluso debe convertirse a sí mismo. Y el primer paso de esa conversión es asumir su estado previo como vivir en la no-verdad.

El segundo es la condición que se requiere para comprender la verdad. Si el que aprende ha de recibir la verdad, deberá disponer también de la condición para comprenderla. Toda enseñanza presupone que la condición esté esencialmente presente o pueda volverse presente en aquel que aprende, pues si no fuera éste el caso no se trataría de transformar o convertir al individuo, sino directamente de recrearlo. Si la condición puede estar presente, pero no está presente, la pérdida de la condición "tiene que haber sido provocada por el propio individuo" ${ }^{44}$. En consecuencia, la no-verdad no sólo es diferente de la verdad, sino que está en contra de la verdad, en tanto en cuanto es el mismo individuo el que pierde la ocasión de la verdad. "¿Cómo podríamos llamar a ese estado de ser la no-verdad y serlo por culpa propia? Llamémosle pecado" ${ }^{45}$. He aquí la condición para recibir la verdad, que no es otra que aquella toma de conciencia del pecado, que Kierkegaard, ya en Ejercitación, había definido como la única puerta de acceso al cristianismo. Para que el iluso pueda salir de su ilusión debe, entonces, aprender la condición para ello; lo que concretamente significa que debe tomar conciencia de que existe en la ilusión y de que su pretendido cristianismo, que rebaja lo Absoluto a lo objetivo, es pecado. He aquí de nuevo el mismo límite para el intento de romper la ilusión que habíamos visto en el peldaño anterior: nadie puede tomar por otro conciencia de su propio pecado. Es el mismo iluso el que debe convertirse aceptando que existe en el pecado. "Dado que estaba en la no-verdad por culpa propia, esa conversión no puede acontecer sin que sea aceptada por su conciencia o sin hacerse consciente él mismo de que era por su culpa" ${ }^{46}$. El iluso debe, por sí mismo, arrepentirse. El maestro a lo sumo podrá promover en él la necesidad de Absoluto, pues "quien goza distraído de los buenos tiempos o está en plena actividad de la mañana a la noche y nunca ha sufrido por

\footnotetext{
${ }^{43}$ Søren Kierkegaard, Migajas Filosóficas, p. 35.

${ }^{44}$ Ibidem.

${ }^{45}$ Ibidem.

${ }^{46}$ Ibíd., p. 38.
} 
causa de la verdad, no la necesita (... ”47. ¿Cómo hacerlo? Kierkegaard no es explícito al respecto, pero, a mi modo de ver, lo que puede hacer el maestro para promover la necesidad de Absoluto en el discípulo pasa por la imitación y la conmoción ante la dignidad. Si la vida del maestro se basa en la contemporaneidad y en la imitación, si, para decirlo en otros términos, el discípulo experimenta en el maestro un ejemplo de interioridad apasionada y una vida puesta al servicio de la venida de un Reino incierto o, lo que es lo mismo, el intento de llevar una relación absoluta con lo Absoluto, entonces él estará ante aquel que es digno de una felicidad absoluta. Y la conmoción que esta dignidad provoca puede llevarlo a la toma de conciencia del pecado y al arrepentimiento de haberse atado a una ilusión y creído digno sin serlo. Como sugiere el propio Kierkegaard, cuando uno es testigo de alguien que ha sido perseguido, vilipendiado, escarnecido por haberse entregado a una buena causa, entonces no dudará de su ascensión a los cielos ni de que es necesaria esta ascensión ${ }^{48}$. Entonces también sentirá en sí mismo la necesidad de Absoluto que lleva a la toma de conciencia del pecado. Sin embargo, la toma de conciencia sigue siendo cuestión de cada uno. Sólo el iluso puede convertirse. Además -y esto sí que resulta inquietante- quizás ningún ejemplo humano de devoción sea suficientemente digno. Por ello sigue siendo imposible volver a otro cristiano. Cada uno debe intentar ser cristiano por obra de su propia decisión.

El último paso es la enseñanza de la verdad misma. Al que vive en la no-verdad, pero se ha arrepentido y tomado conciencia de su pecado, debe aportársele la verdad. Pero si, desde el punto de vista objetivo, el cristianismo -la verdad- es una incertidumbre; y, desde el subjetivo, nadie es cristiano en sentido estricto, entonces ¿cómo será posible enseñar la verdad? ¿Quién, si no es Dios mismo, puede aportarle al otro la verdad? Aquí se muestra, más aún que en los pasos anteriores, la imposibilidad de volver a otro cristiano. La enseñanza, que pretende deshacer la ilusión del falso cristianismo, tal vez, en lo que a este último paso concierne, deba limitarse a una preparación. Ella debe prepararnos para el silencio: para aquel silencio que surge cuando el iluso es, por un instante, apartado del gozo de los buenos tiempos y del alboroto en que se dilapidan los días con sus noches. Debe prepararnos para el silencio "en el que enmudecen los muchos pensamientos del anhelo

\footnotetext{
${ }^{47}$ Søren Kierkegaard, Para un examen de sí mismo recomendado a este tiempo, pp. 87-88.

${ }^{48}$ Cfr. ibíd., p. 89.
} 
y del ansia" 49 . Pues sólo cuando la locuacidad de la ilusión haya callado, sólo cuando impere el silencio, el discípulo podrá escuchar. ¿Escuchar qué? Si se revela una señal. Y ello porque "recién cuando lo Desconocido (lo Eterno) da una señal en la revelación, el hombre percibe su propia conciencia eterna" ${ }^{50}$. Tal vez sea necesaria la humildad para reconocer que nadie le puede enseñar la verdad, el verdadero cristianismo o la verdadera religión, a ningún otro. Tal vez sea necesaria la humildad de limitarse a servir (de volverse siervo) para que el otro encuentre el silencio. Aquel silencio en el que puede escuchar su necesidad de Dios. Porque percibir la propia conciencia eterna es percibir a cada instante, en la intimidad de la conciencia, nuestra necesidad de Absoluto. Bajo las especies de esta necesidad la eternidad nos llama. Ese llamado es su señal. Y su señal es la verdad misma.

\section{Entre religión y filosofía}

Un trabajo que, desde el horizonte del pensamiento kierkegaardiano, se ha propuesto determinar qué significa ser cristiano y cómo puede un individuo singular convertirse en tal, ¿es un escrito religioso o puede tener también alguna significación filosófica? La respuesta es inevitablemente ambigua. Puede ser leído como un escrito de espiritualidad cristiana, pero también como un escrito filosófico. Si se considera que el cristianismo es la verdad absoluta; si se considera, además, que esa verdad ha sido revelada al hombre a través de la encarnación histórica de Dios en Cristo; y si se considera, finalmente, que aprender la verdad es imitar la vida de Cristo, tal cual ésta es narrada en los Evangelios, no cabe duda de que un escrito de esta naturaleza es un escrito religioso.

Pero no creo que sea la única perspectiva de pensamiento ni la única clave de lectura posible. Bien puede pensarse la cuestión desde otros horizontes. Bien puede pensarse que la verdad de la que el cristianismo habla es un Absoluto; una plenitud eterna y definitiva de sentido; un presente incorruptible y no duradero en que cada uno de los seres llega a consumar en armonía la plenitud de sus posibilidades: un Reino ${ }^{51}$. Y también es

${ }^{49}$ Søren Kierkegaard, Los lirios del campo y las aves del cielo, trad. de D. Gutiérrez Rivero, Madrid: Trotta, p. 156.

${ }^{50}$ Richard Purkarthofer, Kierkegaard, Stuttgart: Reclam, 2014, p. 52.

${ }^{51}$ Así lo piensa de hecho Kierkegaard en Los lirios del campo y las aves del cielo, en especial pp. 74-78. 
posible pensar que ese Absoluto, esa "felicidad eterna", que ni podemos definir ni de la cual podemos estar ciertos, destella en el interior de todo hombre en tanto hombre y no sólo en tanto cristiano. ¿Qué nos legitima a pensar tal cosa? ¿Cómo podemos percibir ese destello? Dirigiendo la vista a la existencia humana en cuanto tal. En el propio factum de la realización del espíritu humano se reconoce un don Absoluto, un don incondicionado: el don del espíritu como libertad autoconsciente ${ }^{52}$. Y en el devenir de la libertad humana se reconoce, además, la búsqueda constantemente renovada de un sentido Absoluto, que justifique todos y cada uno de los sentidos parciales de la existencia, pues sin postular un sentido absoluto la existencia misma sería insensata e imposible. Se reconoce, en una palabra, en la propia naturaleza de la existencia, un vínculo originario con lo Absoluto que nos dio nuestro ser como espíritu y una necesidad de re-ligarnos con ese vínculo viviendo tendidos hacia lo Absoluto mismo. Se trata de la necesidad que lo lleva una y otra vez al hombre a participar de la creación, buscando acercar el mundo al Reino deseado. Es - para decirlo sencillamente- aquella necesidad a partir de la cual el hombre existe en el mundo creando una y otra vez sentido. $\mathrm{Y}$ a todas luces es la capacidad de actuar libremente y crear sentido lo que define la condición humana. Por cierto que el espíritu humano es finito y que esa finitud se expresa tanto en el hecho de que nunca alcanza por sí mismo el Absoluto anhelado, cuanto en que las más de las veces se miente a sí mismo y decide tomar por Absoluto lo que es tan sólo relativo. Por cierto, también que el espíritu humano se halla ligado con lo infinito y esa ligazón se manifiesta en el hecho de que, a pesar de que todo lo que él pueda llegar a crear esté destinado a corromperse, una y otra vez vuelve a crear sentido.

Si esto es así, si se puede interpretar el falso cristianismo como la posibilidad humana de negar aquel vínculo originario con y aquella necesidad esencial de Absoluto que distingue al hombre como tal para conformarse enteramente con lo finito, y si se comprende, además, el llegar a ser cristiano como el intento siempre renovado de relacionarnos con lo Absoluto y alcanzar, así, nuestra propia autenticidad como seres espirituales, entonces la cuestión acerca de lo que significa ser cristiano no está divorciada de la cuestión acerca de lo que significa ser hombre, y el llegar a ser cristiano no mienta algo diferente de lo que mienta llegar a ser auténticamente humano. Así leído, un trabajo que versa sobre el problema de cómo llegar a ser cristiano puede también tener una significación filosófica. Así leído, bien

${ }^{52}$ Cfr. nota 13. 
puede este trabajo en la conminación de Kierkegaard para ser auténticos cristianos oír el eco de aquella otra y antigua conminación de Píndaro: "conviértete en quien eres."

\section{Bibliografía}

Furchert, Almut, Das Leiden Fassen. Zur Leidensdialektik Søren Kierkegaards, Freiburg/München: Alber, 2012.

Grøn, Arne, Angst bei Søren Kierkegaard. Eine Einführung in sein Denken, trad. (alemana) U. Lincoln, Stuttgart: Klett-Cotta, 1999.

Heymel, Michael, Möller, Christian, Das Wagnis. Ein Einzelner zu sein. Glauben und Denken Søren Kierkegaards am Beispiel seiner Reden, Zürich: Theologischer Verlag, 2013.

Søren Kierkegaard, Ejercitación del cristianismo, trad. de D. Gutiérrez Rivero, Madrid: Trotta, 2009.

L Los lirios del campo y las aves del cielo, trad. de D. Gutiérrez Rivero, Madrid: Trotta.

— Migajas filosóficas o un poco de filosofía, en Escritos de Søren Kierkegaard. Vol 4/2, trad. de D. González y Ó. Parcero, Madrid: Trotta, 2016.

— Mi punto de vista, trad. de J. M. Velloso, Madrid: Aguilar, 1983.

_ Para un examen de sí mismo recomendado a este tiempo, trad. de A. Albertsen, Madrid: Trotta, 2011.

Postscriptum no cientifico y definitivo a Migajas Filosóficas, trad. de N. Bravo Jordán, México: Universidad Iberoamericana, 2008.

Purkarthofer, Riechard, Kierkegaard, Stuttgart: Reclam, 2014.

Wahl, Jean, Études Kierkegaardiennes, París: Vrin, 1967. 